\title{
Competence-Based EE-Learning: (How) Can We Implement It?
}

\author{
Ton J. Mouthaan, Wouter Olthuis, Henk Vos \\ Twente University, The Netherlands \\ Faculty of Electrical Engineering, Mathematics and Computer Science \\ Corresponding author: a.j.mouthaan@el.utwente.nl
}

\begin{abstract}
There is an enhanced focus the last few years on defining competence-based curricula rather than knowledge based curricula for engineering programs. This drive stems from competence based Human Resource Management where competencies are considered key success factors rather than acquired knowledge and skills alone. Defining learning goals in terms of (tangible) competencies requires some thought but is manageable. Converting these goals to competency-directed education and testing is quite a challenge and almost automatically degrades to easy approachable competencies like 'presentation skills' and avoids the more difficult ones like 'independent learning' or 'design methodology'. In this paper we try to connect also the more difficult competencies or success factors to explicit reflection in project work as a step towards explicit training along the lines of competencies. The first results and appreciation by students are presented. In conclusion, there is still along way to go, but indications are that this is a right track.
\end{abstract}

\section{Introduction}

Personnel managers are used to evaluate their employees in terms of competencies. In Europe large industries have come together to define competency profiles for employees in the IT sector at large (http://www.careerspace.com/index.htm). The transition of the varied European systems of Higher Education to a more transparent Bachelor-Master system that is taking place now brings with it a renewed view on aims and goals of both programs and consequently on skills and knowledge that should be acquired at both levels. A renewed system of accreditation is set up in different countries further enhancing this drive. For the Electrical Engineering bachelor (BSc) and Masters programme (MSc) we have listed and grouped the required competencies in the most tangible terms we can think. Four groups are distinguished where we try to separate competencies as disjoint from each other as possible [1] and figure 1 and table 1. It is obvious that the terminology does not directly lead to knowledge (ability to do Fourier analysis or mixed mode simulation) but stays on a somewhat higher level. Yet for each of the competencies we -as experienced engineers- have no doubt about their importance (the same is true for Fourier or mixed mode simulations). However we are able to translate the latter into courses, but for the former we seem to lack substance to identify and mould into testable 'teaching'.

\section{A competency based curriculum}

The first step to take is to acknowledge that in engineering, competencies relate to abilities to use complexes of knowledge and skills, so they will rarely relate to individual courses. We see no real need to fundamentally change the use of courses as we run them today in a competency-based curriculum. To get to the competency level one must resort to explicit training of the use of complexes of knowledge and skills in projects, as of course we have been doing for years. It does mean that a good EE curriculum needs a well defined set of projects (not necessarily connected to individual courses) throughout to cover all competencies in a structured way. Each project has to focus on a sub-set of competencies and over the complete curriculum we should see a learning curve for the essential competencies. Next challenge is to make the training of competencies explicit and make students see the value of their own learning curves. 


\section{Student reflection on competencies}

Engineering students generally do not enthusiastically dwell on their soft skills, yet they can be triggered if an (in)competency can be directly connected to the way they have done or can improve their projects. We have defined a limited list of open questions that relate to the relevant sub set of competencies for some of the existing projects that have to be answered by the students individually. The questions force them to have a critical look at their actions and provoke an 'aha-erlebniss'. The only requirement (so far) is that students answer the questions seriously (takes 1 or 2 pages); the idea is that answering the questions seriously constitutes the learning activity and it is the level of seriousness (for now) that defines the judgment. This creates quite a lot of material to read for the supervisors and also a portfolio for each student for his learning experience for individual competencies. In the final paper these questions and answers (and pitfalls) will be discussed in more detail.

\section{Conclusions}

Students have responded well to this approach and seem to understand and enjoy the learning experience. On the other hand we are still far from using the competencies we believe in as 'hard' examination criteria.

References: [1] Mouthaan, A.J., Brink, R.W., Vos, H., "Competencies of BSc and MSc programmes in EE and student portfolios", Delta 2002 Conference, http://www.el.utwente.nl/faculteit/delta2002.pdf
Table 1: Competencies in existing projects

\begin{tabular}{|c|c|c|c|c|c|c|c|c|}
\hline \multirow[b]{3}{*}{$\begin{array}{l}\text { Existing } \\
\text { Projects }\end{array}$} & \multicolumn{6}{|c|}{ BSc } & \multirow{2}{*}{\multicolumn{2}{|c|}{\begin{tabular}{|l|} 
MSc \\
$5^{\text {th }}$ year
\end{tabular}}} \\
\hline & \multicolumn{3}{|c|}{$1^{\text {st }} \mathrm{yr}$} & \multicolumn{2}{|c|}{$2^{\text {nd }} \mathrm{yr}$} & \multirow{2}{*}{\begin{tabular}{|l|}
$3^{\text {rd }}$ \\
6
\end{tabular}} & & \\
\hline & 1 & 2 & 3 & 4 & 5 & & 7 & 8 \\
\hline $\begin{array}{l}\text { Duration } \\
\text { (weeks) }\end{array}$ & 1 & 2 & 4 & 2 & 8 & 8 & 14 & 25 \\
\hline \multicolumn{9}{|c|}{ Methodology competencies } \\
\hline 1 & & & & & & & & \\
\hline 2 & & & & & & & & \\
\hline 3 & & & & & & & & \\
\hline 4 & & & & & & & & \\
\hline $5 \ldots \ldots$ & & & & & & & & \\
\hline
\end{tabular}

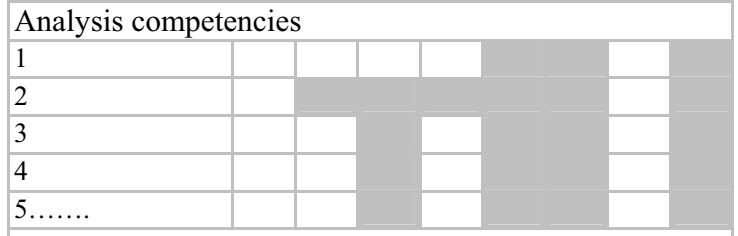

Team work and individual attitude
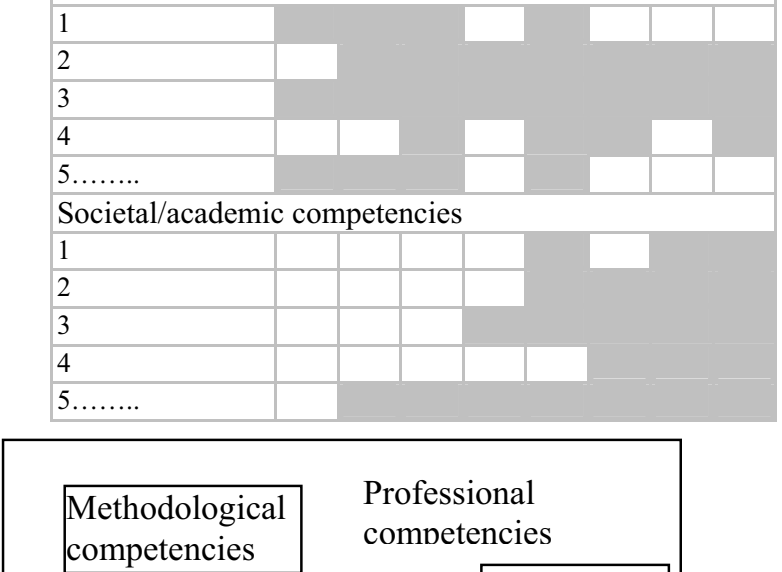

competencies

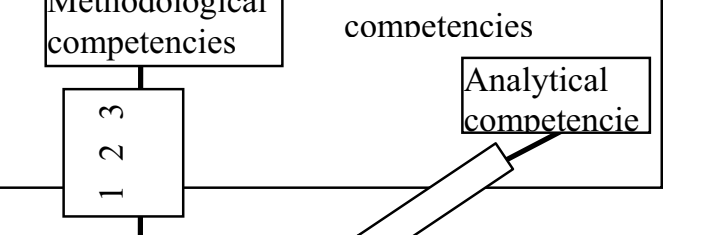

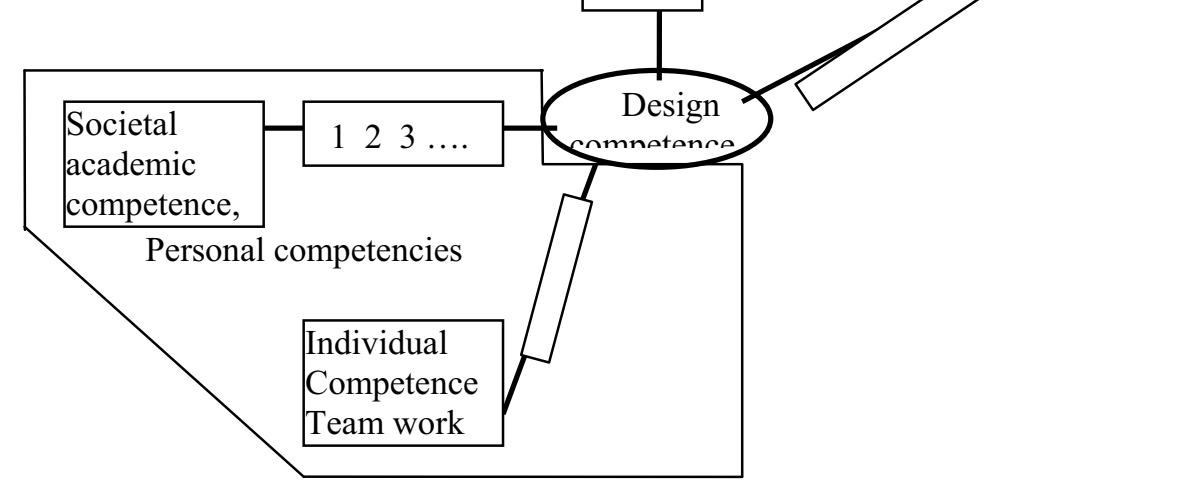

Figure 1: Taxonomy of competencies. 